\title{
Measurement of rapidly available glucose (RAG) in plant foods: a potential in vitro predictor of the glycaemic response
}

\author{
BY HANS N. ENGLYST ${ }^{1}$, JAN VEENSTRA ${ }^{2}$ AND GEOFFREY J. HUDSON ${ }^{1}$ \\ ${ }^{1} M R C$ Dunn Clinical Nutrition Centre, Hills Road, Cambridge CB2 2DH \\ ${ }^{2}$ Hercules European Research Centre, 3770 AK Barneveld, The Netherlands
}

(Received 22 November 1994 - Revised 23 June 1995 - Accepted 4 July 1995)

\begin{abstract}
The glycaemic index (GI) is an in vivo measurement based on the glycaemic response to carbohydratecontaining foods, and allows foods to be ranked on the basis of the rate of digestion and absorption of the carbohydrates that they contain. GI values are normalized to a reference amount of available carbohydrate and do not reflect the amounts of carbohydrate normally present in foods; for example, a food with a low content of carbohydrates will have a high GI value if that carbohydrate is digested and absorbed rapidly in the human small intestine. This is potentially confusing for a person wishing to control his or her blood glucose levels by the choice of foods. The rate and extent of starch digestion in vitro has been measured using a technique that classifies starch into three major fractions: rapidly digestible starch (RDS), slowly digestible starch (SDS) and resistant starch (RS). In addition, this technique gives a value for rapidly available glucose (RAG), which includes RDS, free glucose and the glucose moiety of sucrose. When the values for thirty-nine foods were expressed on the basis of the available carbohydrate content of these foods, highly significant $(P<0.001)$ positive correlations were observed between GI and both RDS and RAG. The measurement of RAG in vitro provides values for direct calculation of the amount of glucose likely to be rapidly absorbed in the human small intestine and, thus, to influence blood glucose and insulin levels. These values can be used to compare foods, as eaten, on an equal-weight basis. Food-table RAG values would allow simple calculation of the total amount of RAG provided by single foods, by whole meals and by whole diets. Studies are planned in which RAG and the glycaemic response in man will be measured for identical food products.
\end{abstract}

Rapidly available glucose: Plant foods: Starch: Glycaemic response

Food analysis, whether for research or for food labelling, should be based on the measurement of chemically identified components, because such values can be grouped or divided as appropriate when new knowledge of their importance to public health becomes available. Dietary carbohydrates may be classified by their degree of polymerization into mono-, di-, oligo- and polysaccharides. Each of these groups may be divided according to the identity of the constituent sugars and type of glycosidic linkage, and then further divided according to other variables of interest. For example, starch may be divided into different types on the basis of susceptibility to enzymic hydrolysis, and NSP may be divided according to their origin, as shown in Table 1.

Analytical methods have been reported for the measurement of NSP (Englyst et al. $1992 b, 1994)$ and the various categories of starch (Englyst et al. 1992a). The measurement of well-characterized carbohydrate fractions should make it possible to predict more fully the glycaemic response to plant foods in terms of the composition of those foods.

The likely effect on the glycaemic response of the various carbohydrate fractions is shown in Table 1. One existing measure of the glycaemic response to food carbohydrate is 
Table 1. Food carbohydrates, fate in the small intestine and glycaemic response

\begin{tabular}{|c|c|c|c|}
\hline Type of carbohydrate & Components & $\begin{array}{l}\text { Hydrolysed } \\
\text { and absorbed } \\
\text { in the small } \\
\text { intestine }\end{array}$ & $\begin{array}{l}\text { Glycaemic } \\
\text { response }\end{array}$ \\
\hline \multirow[t]{2}{*}{ Sugars } & Glucose, sucrose, lactose & Mostly & Large \\
\hline & Fructose & Mostly & Moderate \\
\hline Sugar alcohols & Sorbitol, xylitol, lactitol, maltitol & Sparingly & 0 \\
\hline \multirow[t]{2}{*}{ Short-chain carbohydrates (SC) } & Maltodextrins & Yes & Large \\
\hline & $\begin{array}{l}\text { Resistant SC } \\
\text { (fructo- and galacto-oligosaccharides, } \\
\text { pyrodextrins, polydextrose) }\end{array}$ & No & 0 \\
\hline \multirow[t]{3}{*}{ Starch } & Rapidly digestible starch (RDS)* & Yes & Large \\
\hline & Slowly digestible starch & Yes & Small \\
\hline & Resistant starch & No & 0 \\
\hline Rapidly available glucose (RAG) & RDS + glucose + glucose from sucrose & Yes & Large \\
\hline NSP & $\begin{array}{l}\text { Cellulose, hemicelluloses, pectins, } \\
\text { gums, mucilages }\end{array}$ & No & $0+$ \\
\hline
\end{tabular}

* Includes maltodextrins (partly hydrolysed starch).

$\uparrow$ May affect the glycaemic response to other carbohydrates.

the glycaemic index (GI), which is measured in vivo. The GI is currently defined by Frost et al. (1993) as:

$$
\frac{\text { incremental area under blood glucose response curve for food }}{\text { corresponding area after equi-carbohydrate portion of white bread }} \times 100 \text {. }
$$

The original standard, which is still used by other investigators, was glucose. This was changed due to its sweetness being nauseating to some subjects, and the high osmotic load may cause delayed gastric emptying (Frost et al. 1993). The GI is based on a portion of food containing a standard amount $(50 \mathrm{~g})$ of available carbohydrate (starch plus free sugar). There are a number of factors that can influence the absolute amounts of glucose appearing in the blood during the test period of $2 \mathrm{~h}$ following the meal. These include the rate of gastric emptying and the magnitude of the insulin response (Frost et al. 1993), the degree of chewing (Read et al. 1986), the amylase concentration in the gut (Chapman et al. 1985) and the presence of other food components (Wolever \& Jenkins, 1992).

Sucrose and starch represent the major sources of glucose in the adult human diet. If only foods with the majority of carbohydrates present as starch are considered, however, there are still large differences in the GI values. This must be the result of differences in the rate and/or extent of digestion of the starch in these foods. Studies of the enzymic hydrolysis of starch by pancreatic $\alpha$-amylase (EC 3.2.1 1) in vitro confirm that the proportion of total starch that is rapidly digestible is different for different starchy foods.

The amount of free sugars plus starch varies widely in plant foods and this will influence the glycaemic response to a given amount of food, but not necessarily the GI, which is related to a reference amount of available carbohydrate (see above). The GI is useful for ranking foods in order of the digestibility of the carbohydrate that they contain but, because it is not related directly to the absolute carbohydrate content of the food as eaten, interpretation of GI values is not straightforward. 
The aim of the present study was to investigate to what extent in vitro analytical values (Englyst et al. 1992a) for carbohydrate fractions represent potentially useful predictors of the glycaemic response to foods. The simple measurement of rapidly available glucose (RAG), which includes rapidly digestible starch and free glucose (including that from sucrose), provides values that allow foods to be compared on an as-eaten, equal-weight basis.

\section{MATERIALS AND METHODS}

Glycaemic index

The GI values in the present study were obtained from the literature. To avoid possible differences in the methods used by different research groups, only values measured and reported by the group of Jenkins and Wolever and colleagues (Jenkins et al. 1981, 1984; Wolever, 1990; Wolever \& Jenkins, 1992) were used.

\section{Measurement of different types of starch}

The procedure used to measure rapidly digestible (RDS), slowly digestible (SDS) and resistant (RS) starch fractions has been described in detail elsewhere (Englyst et al. 1992a). Briefly, the various categories of starch were measured after incubation with invertase (EC 3.2.1.26; to hydrolyse sucrose), pancreatic $\alpha$-amylase and amyloglucosidase (EC 3.2.1.3) at $37^{\circ}$ in capped tubes immersed horizontally in a shaking water-bath with a stroke length and speed calibrated to yield predetermined values for a reference material (raw potato starch). All foods that normally require chewing were minced by a standard procedure. The incubation tubes contained glass balls which move from one end of the tube to the other and disrupt the food particles; guar gum was added to standardize the viscosity of the incubation mixture. Foods that are normally eaten warm were cooked immediately before they were taken into the analysis. A value for RAG was obtained as the glucose released from the food after $20 \min \left(G_{20}\right)$. A second measurement $\left(G_{120}\right)$ was obtained as the glucose released after a further $100 \mathrm{~min}$ incubation (120 min incubation in toto). A third measurement (total glucose; TG) was obtained by gelatinization of the starch in boiling water and treatment with $2 \mathrm{M}-\mathrm{KOH}$ at $0^{\circ}$ to disperse any retrograded amylose, followed by complete enzymic hydrolysis with amyloglucosidase. RS is defined as the sum of starch and starch degradation products that, on average, reach the human large intestine (Englyst et al. 1996). It was measured in vitro às the starch that remained unhydrolysed after $120 \mathrm{~min}$ incubation. Separate values could be obtained for different types of RS: physically inaccessible starch $\left(\mathrm{RS}_{1}\right)$, resistant starch granules $\left(\mathrm{RS}_{2}\right)$ and retrograded amylose $\left(\mathrm{RS}_{3}\right)$. Studies with ileostomy patients have shown good agreement between the amount of $\mathrm{RS}$ measured in vitro and the average amount of starch that is not digested in the human small intestine (Englyst et al. 1992a, 1994; Silvester et al. 1995).

Values for RDS and total starch (TS) can be obtained by correcting RAG and TG respectively for free glucose (FG, including the glucose released from sucrose), which is obtained by separate analysis (starch values are calculated as glucose $\times 0.9$ ). SDS is obtained as $\mathrm{G}_{120}-\mathrm{RAG}$. Values for RS can be calculated as the difference between TG and $\mathrm{G}_{120}$, i.e. without the necessity to correct for $F G$, since this is included in both measurements. Values for RAG and RS can be obtained by one simple procedure, as summarized in Fig. 1. The RAG measurement takes only $2-3 \mathrm{~h}$, and RS can be measured well within a working day.

\section{Non-starch polysaccharides}

Total, soluble and insoluble NSP were measured by the enzymic-chemical method of Englyst et al. (1992a) with the GLC end-point for the measurement of individual neutral sugars. 
SAMPLE

+ guar gum

1

Add pepsin in $\mathrm{HCl}$

1

$30 \mathrm{~min}$ at $37^{\circ}$

I

Add sodium acetate

and enzyme mixture (invertase, amylase, amyloglucosidase)

I

Incubate with shaking at $37^{\circ}$

I

After $20 \mathrm{~min}$ remove portion

$$
1
$$

After $20 \mathrm{~min}$ remove portion

Vortex mix remainder

$\stackrel{1}{\min }$ at $100^{\circ}$

30 min at $100^{\circ}$

Cool to $0^{\circ}$; add $\mathrm{KOH}$

Vortex mix

$$
1
$$

$30 \mathrm{~min}$ at $0^{\circ}$ with shaking

1

Vortex mix; take portion into

acetic acid

Add amyloglucosidase

30 min at $70^{\circ}$

$10 \stackrel{\mathrm{min}}{\mathrm{m}}$ at $100^{\circ}$

Cool, dilute and centrifuge
।
Measure TG

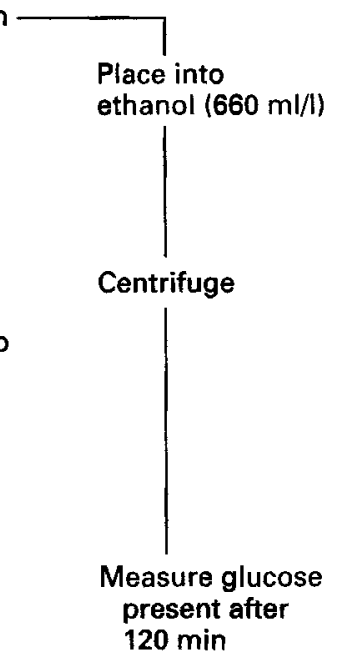

MG
$\mathrm{G}_{120}$

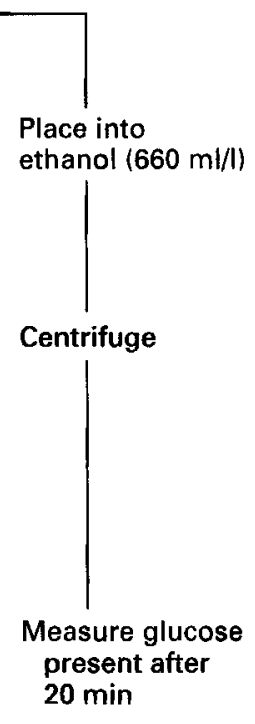

RAG

Fig. 1. A summary of the analytical strategy for measurement of rapidly available glucose (RAG), total glucose (TG) and the glucose released by $120 \mathrm{~min}$ of incubation $\left(G_{120}\right)$ in the same sample without the necessity to measure free glucose, which requires analysis of a separate sample. Resistant starch (RS) is calculated as $T G-G_{120}$. For details, see p. 329.

\section{Samples}

All foods for analysis were bought in Cambridge. The foods that normally require processing were cooked according to the instructions on the package, or by normal cooking practice for products bought loose; e.g. potatoes, sweet potatoes (Ipomoea batatas) and yam (Dioscorea batatas).

\section{RESULTS}

Thirty-nine starchy foods for which GI values have been published were selected and analysed for their carbohydrate content as described on p. 329; the results are shown in Table 2.

\section{Correlations}

Analytical values for the carbohydrate fractions (Table 2) were divided by the available carbohydrate content of each food (calculated as TS $+2 \mathrm{FG}$; see p. 329) for comparison with the published GI values by linear least-squares regression analysis. There was a weak but significant inverse correlation between GI and total NSP, and between both soluble and 
Table 2. The carbohydrate content of thirty-nine starchy foods $(\mathrm{g} / 100 \mathrm{~g} \text { as eaten })^{*}$

\begin{tabular}{|c|c|c|c|c|c|c|c|c|c|c|c|}
\hline & \multirow[b]{2}{*}{ DM } & \multirow[b]{2}{*}{ TG } & \multirow[b]{2}{*}{ FG } & \multirow[b]{2}{*}{ TS } & \multirow[b]{2}{*}{ RDS } & \multirow[b]{2}{*}{ SDS } & \multirow[b]{2}{*}{ RS } & \multirow[b]{2}{*}{ RAG } & \multicolumn{3}{|c|}{ NSP } \\
\hline & & & & & & & & & Soluble & Insoluble & Total \\
\hline \multicolumn{12}{|l|}{ Cereals } \\
\hline Pearled barley & $41 \cdot 1$ & $19 \cdot 1$ & $0 \cdot 1$ & $17 \cdot 1$ & $8 \cdot 0$ & $7 \cdot 0$ & $2 \cdot 1$ & $9 \cdot 0$ & 1.6 & $3 \cdot 2$ & 48 \\
\hline Buckwheat & $30 \cdot 3$ & $24 \cdot 7$ & $0 \cdot 1$ & $22 \cdot 1$ & $11 \cdot 8$ & $8 \cdot 5$ & 1.8 & $13 \cdot 2$ & 0.4 & 0.4 & 0.8 \\
\hline Sweetcorn & $28 \cdot 8$ & $19 \cdot 7$ & $0-7$ & $17 \cdot 1$ & $15 \cdot 4$ & $1 \cdot 4$ & $0 \cdot 3$ & $17 \cdot 8$ & 0.6 & $2 \cdot 7$ & $3 \cdot 3$ \\
\hline \multicolumn{12}{|l|}{ Bread } \\
\hline White & $61 \cdot 2$ & $46 \cdot 4$ & $0 \cdot 1$ & $41 \cdot 7$ & $37 \cdot 4$ & 3.7 & 0.6 & $41 \cdot 7$ & $1 \cdot 0$ & 0.7 & $1 \cdot 7$ \\
\hline Wholemeal & $58 \cdot 1$ & $39 \cdot 2$ & $0 \cdot 4$ & $35 \cdot 0$ & $32 \cdot 1$ & $1 \cdot 4$ & $1 \cdot 5$ & $36 \cdot 1$ & 1.8 & $3 \cdot 5$ & $5 \cdot 3$ \\
\hline Rye wholemeal & $63 \cdot 1$ & 38.9 & $1 \cdot 4$ & $33 \cdot 8$ & $23 \cdot 2$ & $7 \cdot 4$ & $3 \cdot 2$ & 27.2 & $4 \cdot 2$ & $4 \cdot 2$ & $8 \cdot 4$ \\
\hline Ryvita crispbread & $93 \cdot 8$ & $67 \cdot 4$ & $1 \cdot 1$ & $59 \cdot 8$ & $48 \cdot 8$ & $6 \cdot 7$ & $4 \cdot 3$ & $55 \cdot 3$ & $3 \cdot 8$ & $7 \cdot 7$ & $11 \cdot 5$ \\
\hline \multicolumn{12}{|l|}{ Biscuits } \\
\hline Digestive & $98 \cdot 0$ & $59 \cdot 8$ & $8 \cdot 1$ & $46 \cdot 5$ & 32.0 & $12 \cdot 6$ & 1.9 & $43 \cdot 7$ & $1 \cdot 1$ & $1 \cdot 1$ & $2 \cdot 2$ \\
\hline Oatmeal & $98 \cdot 6$ & $62 \cdot 6$ & 0.4 & $55 \cdot 9$ & 48.8 & $6 \cdot 2$ & 0.9 & $54 \cdot 6$ & $4 \cdot 1$ & $3 \cdot 4$ & 7.5 \\
\hline Rich Tea & $98 \cdot 4$ & 629 & $8 \cdot 7$ & $48 \cdot 8$ & $38 \cdot 6$ & 8.9 & $1 \cdot 3$ & $51 \cdot 6$ & $1 \cdot 1$ & 0.6 & 1.7 \\
\hline Water & $95 \cdot 5$ & $78 \cdot 0$ & 0.4 & $69 \cdot 8$ & $65 \cdot 4$ & $3 \cdot 8$ & 0.6 & $73 \cdot 1$ & $1 \cdot 7$ & $1 \cdot 2$ & $3 \cdot 0$ \\
\hline \multicolumn{12}{|l|}{ Breakfast cereals } \\
\hline All Bran & $86 \cdot 0$ & $37 \cdot 2$ & $12 \cdot 4$ & $22 \cdot 2$ & 20.6 & 0.5 & $1 \cdot 1$ & $35 \cdot 3$ & 3.6 & $18 \cdot 1$ & $21 \cdot 1$ \\
\hline Porridge oats & $23 \cdot 6$ & $14 \cdot 6$ & $0 \cdot 1$ & $13 \cdot 0$ & 9.9 & $3 \cdot 1$ & 0.1 & $11 \cdot 1$ & 0.9 & 0.7 & $1 \cdot 7$ \\
\hline Shredded Wheat & $91 \cdot 7$ & $70 \cdot 0$ & 0.9 & $62 \cdot 2$ & $48 \cdot 7$ & $11 \cdot 9$ & 1.6 & $55 \cdot 0$ & $2 \cdot 0$ & $7 \cdot 8$ & $9 \cdot 8$ \\
\hline Puffed Wheat & $90 \cdot 8$ & $77 \cdot 4$ & $1 \cdot 0$ & $68 \cdot 7$ & $62 \cdot 5$ & $0 \cdot 0$ & $6 \cdot 2$ & $70 \cdot 4$ & $2 \cdot 3$ & $5 \cdot 3$ & $7-5$ \\
\hline Weetabix & $94 \cdot 2$ & $65 \cdot 5$ & $2 \cdot 2$ & 57.0 & $56 \cdot 8$ & 1.0 & 0.0 & $65 \cdot 3$ & $3 \cdot 1$ & $6 \cdot 6$ & $9 \cdot 7$ \\
\hline Oat bran & $95 \cdot 6$ & $51 \cdot 8$ & $1 \cdot 0$ & $45 \cdot 8$ & $31 \cdot 2$ & $13 \cdot 6$ & 1.0 & 35.7 & $8 \cdot 0$ & $5 \cdot 1$ & $13 \cdot 1$ \\
\hline Rice Krispies & $96 \cdot 5$ & $85 \cdot 0$ & $7 \cdot 4$ & $69 \cdot 8$ & $65 \cdot 6$ & $1 \cdot 7$ & $2 \cdot 5$ & $80 \cdot 3$ & $0 \cdot 1$ & 0.4 & $0-5$ \\
\hline \multicolumn{12}{|l|}{ Cooked rice } \\
\hline \multirow{2}{*}{$\begin{array}{r}\text { Long grain: White } \\
\text { Brown }\end{array}$} & $32 \cdot 5$ & $25 \cdot 6$ & $0 \cdot 0$ & $23 \cdot 0$ & $17 \cdot 4$ & $5 \cdot 6$ & 0.0 & $19 \cdot 3$ & 0.0 & $0 \cdot 2$ & 0.2 \\
\hline & $37 \cdot 7$ & 26.4 & $0 \cdot 1$ & $23 \cdot 8$ & 14.6 & $9 \cdot 2$ & 0.0 & $16 \cdot 3$ & 0.0 & $0-8$ & 0.8 \\
\hline Parboiled & $31 \cdot 2$ & $31-0$ & 0.1 & $27 \cdot 8$ & $16 \cdot 6$ & $10 \cdot 0$ & 1.2 & $18 \cdot 5$ & 0.0 & $0-2$ & $0 \cdot 2$ \\
\hline \multicolumn{12}{|l|}{ Pasta } \\
\hline Macaroni & $31 \cdot 0$ & $29 \cdot 3$ & 0.2 & $26 \cdot 2$ & $13 \cdot 4$ & $12 \cdot 0$ & 0.8 & $15 \cdot 1$ & 0.5 & $0 \cdot 4$ & $0 \cdot 9$ \\
\hline White spaghetti & $31 \cdot 7$ & $26 \cdot 2$ & 0.1 & $23 \cdot 5$ & $13 \cdot 5$ & $9 \cdot 0$ & 1.0 & $15 \cdot 1$ & 0.5 & 0.5 & $1 \cdot 0$ \\
\hline \multicolumn{12}{|l|}{ Legumes } \\
\hline Butter beans & $33 \cdot 0$ & $13 \cdot 0$ & 0.3 & $11 \cdot 4$ & $9 \cdot 4$ & 0.8 & $1 \cdot 2$ & 10.7 & $2 \cdot 4$ & $3 \cdot 4$ & $5 \cdot 9$ \\
\hline Haricot beans & $32 \cdot 6$ & $20 \cdot 5$ & 0.3 & $18 \cdot 2$ & $4 \cdot 1$ & $5 \cdot 8$ & $8 \cdot 3$ & 4.9 & 3.0 & $3 \cdot 7$ & $6 \cdot 6$ \\
\hline Kidney beans & 33.0 & $19 \cdot 3$ & $0 \cdot 4$ & $17 \cdot 0$ & $4 \cdot 7$ & $9 \cdot 8$ & $2 \cdot 5$ & $5 \cdot 6$ & $3 \cdot 0$ & $3 \cdot 3$ & $6 \cdot 3$ \\
\hline Pinto beans & $40 \cdot 1$ & $18 \cdot 3$ & $0 \cdot 4$ & $16 \cdot 1$ & $9 \cdot 3$ & $5 \cdot 0$ & $1 \cdot 8$ & $10 \cdot 7$ & $3 \cdot 2$ & $3 \cdot 6$ & $6 \cdot 8$ \\
\hline Kidney beans (canned) & $32 \cdot 0$ & $16 \cdot 9$ & 0.7 & $14 \cdot 6$ & $7 \cdot 6$ & $5 \cdot 2$ & 1.8 & $9 \cdot 1$ & 2.9 & $3 \cdot 2$ & $6 \cdot 1$ \\
\hline Beans in tomato sauce & $24 \cdot 0$ & $9 \cdot 6$ & $0 \cdot 5$ & $8 \cdot 2$ & $5 \cdot 5$ & $1 \cdot 2$ & $1 \cdot 5$ & 6.6 & $2 \cdot 0$ & $1 \cdot 2$ & $3 \cdot 2$ \\
\hline Chickpea (garbanzo) & $33 \cdot 5$ & $18 \cdot 4$ & $0 \cdot 2$ & $16 \cdot 4$ & $5 \cdot 1$ & $8 \cdot 8$ & $2 \cdot 5$ & $5 \cdot 9$ & 1.4 & $2 \cdot 8$ & $4 \cdot 2$ \\
\hline Marrowfat peas & $30 \cdot 7$ & $17 \cdot 5$ & 0.4 & $15 \cdot 4$ & $7 \cdot 4$ & $5 \cdot 0$ & $3 \cdot 0$ & $8 \cdot 6$ & 1.4 & $3 \cdot 3$ & $4 \cdot 6$ \\
\hline Frozen peas & $21 \cdot 8$ & $9 \cdot 2$ & $1 \cdot 2$ & $7 \cdot 2$ & $4 \cdot 1$ & $1 \cdot 0$ & $2 \cdot 1$ & $5 \cdot 8$ & $1 \cdot 6$ & $3 \cdot 6$ & $5 \cdot 2$ \\
\hline Chickpea (canned) & $31 \cdot 0$ & $17 \cdot 8$ & 0.3 & $15 \cdot 8$ & $9 \cdot 2$ & $3 \cdot 8$ & $2 \cdot 8$ & $10 \cdot 5$ & $1 \cdot 3$ & $2 \cdot 6$ & $3 \cdot 9$ \\
\hline Red lentils & $27 \cdot 4$ & $17 \cdot 8$ & 0.2 & $15 \cdot 8$ & $7 \cdot 3$ & $6 \cdot 1$ & $2 \cdot 4$ & $8 \cdot 3$ & 0.5 & $1 \cdot 1$ & 1.6 \\
\hline \multicolumn{12}{|l|}{ Other } \\
\hline Potato & $21 \cdot 3$ & $18 \cdot 0$ & 0.2 & $16 \cdot 0$ & $15 \cdot 2$ & 0.7 & 0.1 & $17 \cdot 1$ & 0.7 & 0.7 & $1 \cdot 4$ \\
\hline Instant potato & $24 \cdot 2$ & $14 \cdot 4$ & $0 \cdot 3$ & $12 \cdot 7$ & $10 \cdot 9$ & $1 \cdot 1$ & 0.8 & $12 \cdot 4$ & 0.8 & 0.8 & $1 \cdot 6$ \\
\hline Potato crisps & $98 \cdot 2$ & $56 \cdot 0$ & 0.4 & $50 \cdot 0$ & $42 \cdot 7$ & $2 \cdot 8$ & $4 \cdot 5$ & $47 \cdot 8$ & $1 \cdot 0$ & 12 & $2 \cdot 1$ \\
\hline Yam & $32 \cdot 6$ & $20 \cdot 3$ & 1.7 & $16 \cdot 8$ & $14 \cdot 3$ & 0.4 & $2 \cdot 1$ & $17 \cdot 6$ & 0.6 & 0.7 & $1 \cdot 2$ \\
\hline Sweet potato & $24 \cdot 3$ & $12 \cdot 6$ & $2 \cdot 3$ & $9 \cdot 3$ & $7 \cdot 5$ & 0.8 & $1 \cdot 1$ & $10 \cdot 6$ & 0.9 & $1 \cdot 1$ & 20 \\
\hline
\end{tabular}

TG, total glucose; FG, free glucose, including that from sucrose; TS, total starch; RDS, rapidly digestible starch; SDS, slowly digestible starch; RS, resistant starch; RAG, rapidly available glucose (calculated as the sum of glucose from RDS and FG).

* For details of procedures, see pp. 329-330. 


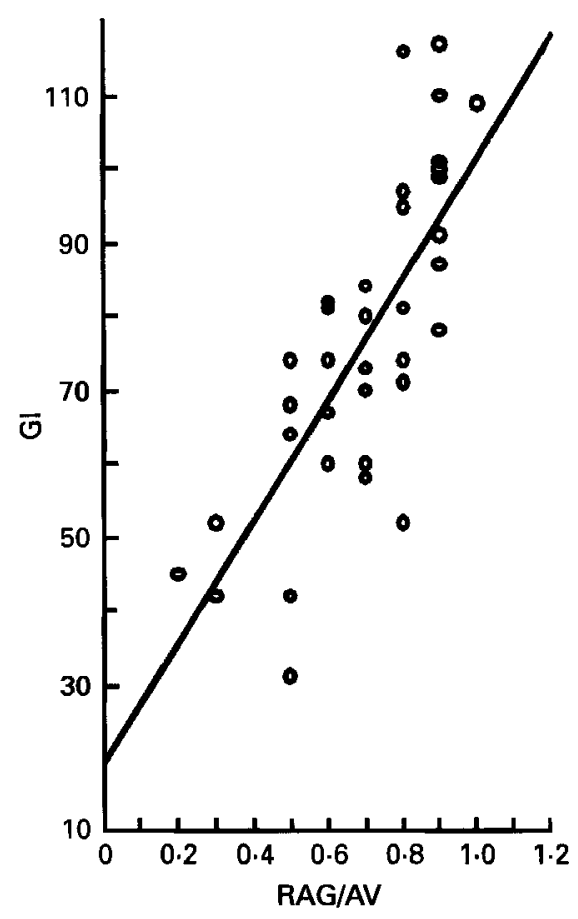

Fig. 2. The linear least-squares regression of glycaemic index (GI) values from the literature (Jenkins et al. 1981, 1984; Wolever, 1990; Wolever \& Jenkins, 1992) on values for rapidly available glucose (RAG) divided by available carbohydrate (RAG/AV) is shown with the line of best fit (for details, see p. 330).

insoluble NSP $(P<0.05$ in each case). There was, as expected, a highly significant positive correlation between the GI values and those for RDS $(r 0.728, P<0.001)$ and those for RAG ( $r 0.760, P<0.001$; see Fig. 2$)$.

Table 3 shows the thirty-nine foods ranked by values for the RAG content $(\mathrm{g} / 100 \mathrm{~g})$ of foods as eaten and the GI values for those foods. The ranking for many foods was not very different between the two systems. However, there were some dramatic differences; for example, the rankings for the instant potato and new potato were quite different under the two systems. The starch in these products was readily digestible, which resulted in a high GI score, but the solids content of these foods as eaten was low, which led to a low RAG value.

\section{DISCUSSION}

The present work reports the analysis of the carbohydrate content of thirty-nine starchy foods. The objectives of this work were (1) to explain the differences in glycaemic response for starchy foods, and (2) to identify any carbohydrate fraction that could be measured in vitro and used as a meaningful predictor of the glycaemic response.

\section{Digestibility of starch}

The present study used the GI values measured and reported by Jenkins and Wolever and colleagues (Jenkins et al. 1981, 1984; Wolever, 1990; Wolever \& Jenkins, 1992). In general, values measured by other groups are very similar and confirm the generally low glycaemic responses to legumes and the higher responses for many cereal products (Jenkins $e t$ al. 1984; Walker \& Walker, 1984). 
Table 3. The thirty-nine starchy foods are ranked by rapidly available glucose $(R A G) *$ and shown with glycaemic index $(G I)$ values taken from the literature $\dagger$

\begin{tabular}{|c|c|c|}
\hline Food & $\underset{(\mathrm{g} / 100 \mathrm{~g})}{\mathbf{R A G}}$ & GI \\
\hline Haricot bean & 4 & 45 \\
\hline Kidney bean & 5 & 42 \\
\hline Chickpea (garbanzo) & 5 & 52 \\
\hline Frozen pea & 5 & 74 \\
\hline Beans in tomato sauce & 6 & 60 \\
\hline Red lentil & 8 & 42 \\
\hline Marrowfat pea & 8 & 68 \\
\hline Potato (new) & 8 & 101 \\
\hline Pearled barley & 8 & 31 \\
\hline Kidney bean (canned) & 8 & 74 \\
\hline Chickpea (canned) & 10 & 60 \\
\hline Butter bean & 10 & 52 \\
\hline Pinto bean & 10 & 60 \\
\hline Sweet potato & 10 & 70 \\
\hline Buckwheat & 12 & 74 \\
\hline Instant potato & 12 & 116 \\
\hline Macaroni & 14 & 64 \\
\hline White spaghetti & 14 & 67 \\
\hline Brown rice & 15 & 96 \\
\hline Yam & 16 & 74 \\
\hline Sweetcorn & 16 & 87 \\
\hline Parboiled rice & 17 & 67 \\
\hline White rice & 17 & 83 \\
\hline Rye wholemeal bread & 25 & 58 \\
\hline Oat bran & 32 & 84 \\
\hline Wholemeal bread & 33 & 99 \\
\hline All Bran & 33 & 73 \\
\hline White bread & 38 & 100 \\
\hline Digestive biscuit & 40 & 82 \\
\hline Porridge oats & 42 & 71 \\
\hline Potato crisps & 43 & 74 \\
\hline Rich Tea biscuit & 48 & 80 \\
\hline Oatmeal biscuit & 49 & 78 \\
\hline Shredded Wheat & 50 & 97 \\
\hline Ryvita crispbread & 50 & 95 \\
\hline Weetabix & 59 & 109 \\
\hline Puffed Wheat & 64 & 110 \\
\hline Water biscuit & 66 & 91 \\
\hline Rice Krispies & 73 & 117 \\
\hline
\end{tabular}

* For details of procedures, see pp. 329-330.

$\dagger$ Values taken from Jenkins et al. (1981, 1984), Wolever (1990) and Wolever \& Jenkins (1992).

Some starch is physically inaccessible to hydrolytic enzymes because it is trapped within plant cell walls or food particles and becomes available for digestion only when the particles are broken down. In the case of pearled barley, macaroni and white spaghetti, for example, particles of the food could be seen in the incubation mixture after 20 min of incubation. In macaroni and spaghetti these particles had disappeared after 120 min incubation. In pearled barley, however, particles remained after $120 \mathrm{~min}$ of incubation and the starch they contain was measured as $\mathrm{RS}_{1}$, physically inaccessible starch. Studies in vivo have shown the influence of food particle size on starch digestibility. Decreasing the size of flour particles 
used for baking has been shown to reduce both glucose and insulin responses (Heaton $e t$ al. 1988), and marked differences in glycaemic response and satiety have been demonstrated for equal amounts of apples eaten as whole fruit, pulp or juice (Haber et al. 1977). Swallowing without chewing has been shown to be an effective way to lower postprandial glycaemic responses to foods (Read et al. 1986).

The type of crystal structure present in starch granules may influence its digestibility (Katz \& Van Itallie, 1930; Katz, 1934, 1937; Sterling, 1978). For example, potato and banana (Musa paradisiaca sapientum) starch granules are of type B, which is highly resistant to digestion by pancreatic amylase and is measured as $\mathrm{RS}_{2}$. Beans and peas (Pisum sativum) are especially rich in type $\mathrm{C}$ starch, which is somewhat resistant to hydrolysis by $\alpha$-amylase, and this, together with encapsulation by the thick plant cell walls (dietary fibre), may be related to the relatively large proportions of SDS and RS measured in most of the legumes.

Cooked starch, once cooled, may contain regions where the starch chains (mainly amylose) have aggregated into a configuration with a very low level of susceptibility to pancreatic amylase, and that would reach the large intestine as $\mathrm{RS}_{3}$. The gelatinization of starch granules and the retrogradation of starch on cooling during food preparation clearly influences the physical structure and, hence, the digestibility of starchy foods, some of which are inedible without some form of food processing.

The digestibility of the starch in starchy foods, as reported here, is dependent on a number of factors other than those mentioned previously. In manufactured foods, differences occur in the origin of raw ingredients, in composition, in food-processing procedures, and the time and conditions of storage of the food before it is eaten. Factors that may influence the digestibility of starch in food bought raw, besides food processing, are its origin, its ripeness at the time of harvest, and its ripeness at the time of eating, for example for bananas (Englyst \& Cummings, 1986).

All factors that may influence the digestibility of starch in a given food apply to the GI. The GI values used in the present study were taken from the literature; they were not measured at the same time or for the same foods that were used for the starch-digestibility measurements. In addition, the GI is influenced by a number of factors that do not play a role in the digestibility of starch in vitro, such as the rate of gastric emptying, which may be influenced by the amount of fat and NSP in the food, and the rate of glucose absorption over the intestinal unstirred layer. Further differences occur both within and between individuals, such as the extent of chewing, the amount of pancreatic amylase produced, and the amount of insulin produced (Frost et al. 1993).

Differences in the rate of starch digestion provide a plausible mechanism for differences in glycaemic responses to starchy foods. It explains why most breakfast cereals have high GI values, why pastas in general have low GI values, and it may explain why the glycaemic response to pasta is not influenced by increasing its cooking time (Wolever et al. 1986; Bornet et al. 1990), as long as the general structure remains intact. The cooking time of legumes, on the other hand, does influence the blood glucose response, and the digestibility of starch in vitro (Jenkins et al. 1982), probably because of the slow swelling, and only partial gelatinization of the starch from whole legumes. If the matrix of the legumes is disrupted by milling before cooking, the digestibility of the starch is greatly enhanced (Würsch et al. 1986).

Part of the slow rate of digestion of the starch in some foods is clearly the result of starch being trapped within cell-wall structures. The starch in brown rice, for example, was digested in vitro much more slowly than that in white rice. If starch is trapped very firmly within cell-wall structures it may resist digestion in the small intestine completely and it will be measured in vitro as RS $_{1}$ (physically inaccessible starch; Englyst et al. 1992a). The GI 
values for white (83) and brown rice (96) given by Jenkins et al. (1984) are in contrast to these observations; it is possible that the brown rice was chewed more thoroughly.

\section{Prediction of the glycaemic response}

When analytical values are expressed as RDS $\div$ available carbohydrate and $\mathrm{RAG} \div$ available carbohydrate there is a close correlation between these variables and published GI values for these foods. This approach was taken to express the analytical values on a basis similar to that used for the calculation of the GI values. Traditionally, GI values are calculated as the area under the plasma glucose response curve when an amount of food equivalent to $50 \mathrm{~g}$ available carbohydrate is used as the test meal, and then normalized to the response to a standard meal, originally glucose but here white bread. There may be a discrepancy between the values used for available carbohydrate. In the present work, available carbohydrate is calculated as TS $+2 \mathrm{FG}$, which includes all RS. It is probable, however, that the values for starch and FG (designated available carbohydrate) that were used for calculation of the GI will not have included all RS, and especially not all the RS formed as the result of food processing, i.e. $\mathrm{RS}_{3}$. Nevertheless, the amounts of $\mathrm{RS}_{3}$ in these foods is small and unlikely to have influenced the conclusions significantly.

GI values cannot be used for direct comparison of foods on an equal-weight basis; knowledge of the amounts of carbohydrates in foods is required in addition. In contrast, RDS and RAG values can be used directly to compare foods on an equal-weight basis. RAG values may be used to calculate the sum of glucose likely to be rapidly absorbed simply from the identity and weights of foods comprising a meal or diet.

Table 3 shows the ranking of the thirty-nine starchy foods analysed in the present study on the basis of absolute values for RAG, which take into account the amount of RAG in foods, and the GI values for these foods, which describe the digestibility but not the amount of carbohydrates present in a food. The biggest difference is seen for new potatoes; these have a high GI score because the starch they contain is readily digestible, but a low RAG score because cooked potatoes have a low solids content. With the exception of All Bran, the breakfast cereals have high scores in both these systems. RAG values can be expressed on a per $100 \mathrm{~g}$ (Table 3 ) or a portion size basis and, thus, would be readily interpretable. If the RAG values of foods, as is suggested by the present study, are shown to be reliable predictors of the glycaemic response in vivo, these values will be of direct use to consumers, dietitians and others working in areas where the control of the glycaemic response is of importance. In the same way, food-table values for RAG could be used for simple calculation of the total amount of RAG provided by mixed meals and for the formulation of diets for special purposes.

The effect of calculating RAG contents on a portion basis is illustrated by examining a subset of the foods analysed, using average portion sizes (Crawley, 1988). If six foods representing the range of RAG values are ranked, we have:

(1) per $100 \mathrm{~g}$ : Peas < potatoes $<$ white rice $<$ potato crisps $<$ Shredded Wheat $<$ Rice Krispies,

(2) per average portion: Peas $<$ potato crisps $<$ potatoes $<$ Shredded Wheat $<$ Rice Krispies $<$ white rice,

where the largest effect is seen for white rice. Although the potato crisps and breakfast cereals have the highest RAG values, their average portion size (crisps $25 \mathrm{~g}$, Rice Krispies $30 \mathrm{~g}$, Shredded Wheat $35 \mathrm{~g}$ ) is much smaller than that for white rice $(150 \mathrm{~g})$. Despite the small portion size for breakfast cereals compared with that of potatoes $(180 \mathrm{~g})$, these cereal products represent a greater source of RAG per portion, reflecting the differences in water content of these foods as eaten.

The glycaemic response is the net result of the absorption of glucose in the human small 
intestine. As well as the carbohydrate composition of foods, many extrinsic factors can affect the magnitude of the response; for example, the extent to which food is chewed, transit time through the gut and the magnitude of the insulin response.

The results presented here suggest (from the analysis of variance associated with the regression of GI $v$. normalized RAG) that approximately $61 \%$ of the glycaemic response measured in vivo can be accounted for by simple measurement of RAG in vitro. Like the GI values, the RAG values are independent of the proportions of glucose obtained from free glucose, sucrose or starch. Both are measures related to the rate and extent of digestion and absorption of carbohydrate; in addition, RAG, as shown here, is the single major determinant of the magnitude of the glycaemic response.

Studies are planned in which RAG and the glycaemic response in man will be measured for identical food products.

\section{Conclusions}

The close correlation between the RDS values for the foods analysed here and the GI values from the literature explains the differences in glycaemic response for foods with similar contents of starch, and emphasizes the importance of being able to measure in vitro the proportion of starch that, on average, is likely to be digested rapidly in the human small intestine.

It is important to recognize the difference in concept between GI values, which reflect the digestibility but not the amount of carbohydrates in foods, and RAG values, which are based on a given weight of food as eaten and can be used directly in the calculation of the total RAG value for a meal or diet.

The use of RAG values rather than RDS values extends the usefulness of the in vitro analysis to non-starchy foods, since RAG values are not restricted by the source of glucose.

The weak but significant inverse correlations observed between NSP and GI for the starchy foods in the present study reflect the fact that the encapsulation of sugars and starch within plant cell walls (dietary fibre) can delay or even prevent their digestion and absorption in the human small intestine, leading to lower RAG and GI values. This contribution to the moderation of the glycaemic response, and hence plasma glucose levels, is one of the benefits associated with the unfortified, high-fibre diet rich in fruit, vegetables and high-extraction cereal products that is recommended in national consumer guidelines. It is clearly not possible to confer this advantage by the addition of fibre supplements to highly processed foods in which the structure of the plant cells has been largely destroyed and their contents made available for rapid digestion and absorption.

\section{REFERENCES}

Bornet, F. R. J., Cloaree, D., Barry, J. L., Colonna, P., Gouilloud, S., Laval, J. D. \& Galmiche, J. P. (1990). Pasta cooking time: influence on starch digestion and plasma glucose and insulin responses in healthy subjects. American Journal of Clinical Nutrition 51, 421-427.

Chapman, R. W., Sillery, J. K., Graham, M. M. \& Saunders, D. R. (1985). Absorption of starch by healthy ileostomates: effects of transit time and of carbohydrate load. American Journal of Clinical Nutrition 41, $1244-1248$.

Crawley, H. (1988). Food Portion Sizes. London: H.M. Stationery Office.

Englyst, H. N. \& Cummings, J. H. (1986). Digestion of the carbohydrates of banana (Musa paradisiaca sapientum) in the human small intestine. American Journal of Clinical Nutrition 44, 42-50.

Englyst, H. N., Kingman, S. M. \& Cummings, J. H. (1992a). Classification and measurement of nutritionally important starch fractions. European Journal of Clinical Nutrition 46, S33-S50.

Englyst, H. N., Kingman, S. M., Hudson, G. J. \& Cummings, J. H. (1996). Measurement of resistant starch in vitro and in vivo. British Journal of Nutrition (In the Press).

Englyst, H. N., Quigley, M. E. \& Hudson, G. J. (1994). Determination of dietary fibre as non-starch polysaccharides with gas-liquid chromatographic, high-performance liquid chromatographic or spectrophotometric measurement of constituent sugars. Analyst 119, 1497-1509. 
Englyst, H. N., Quigley, M. E., Hudson, G. J. \& Cummings, J. H. (1992b). Determination of dietary fibre as nonstarch polysaccharides by gas-liquid chromatography. Analyst 117, 1707-1714.

Frost, G., Wolever, T. M. S. \& Leeds, A. R. (1993). Review: the glycaemic index. Is it time to take a new look? Dietary Fiber Bibliography and Reviews 1, 66-71.

Haber, G. B., Heaton, K. W., Murphy, D. \& Burroughs, L. F. (1977). Depletion and disruption of dietary fibre. Effects on satiety, plasma-glucose, and serum-insulin. Lancet ii, 679-682.

Heaton, K. W., Marcus, S. N., Emmett, P. M. \& Bilton, C. H. (1988). Particle size of wheat, maize and oat test meals: effects on plasma glucose and insulin responses and on the rate of starch digestion in vitro. American Journal of Clinical Nutrition 47, 675-682.

Jenkins, D. J. A., Thorne, M. J., Cameleon, K., Jenkins, A., Rao, A. V., Taylor, R. H., Thompson, L. U., Kalmusky, J., Reichert, R. \& Francis, T. (1982). Effect of processing on digestibility and the blood glucose response: a study in lentils. American Journal of Clinical Nutrition 36, 1093-1101.

Jenkins, D. J. A., Wolever, T. M. S., Jenkins, A. L., Josse, R. G. \& Wong, G. S. (1984). The glycaemic response to carbohydrate foods. Lancet ii, 388-391.

Jenkins, D. J. A., Wolever, T. M. S., Jenkins, A. L., Thompson, L. U., Rao, A. V. \& Francis, T. (1986). The glycaemic index: blood glucose response to foods. In Dietary Fibre. Basic and Clinical Aspects, pp. 167-179 [G. V. Vahouny and D. Kritchevsky, editors]. New York: Plenum Press.

Jenkins, D. J. A., Wolever, T. M. S., Taylor, R. H., Barker, H., Fielden, H., Baldwin, J. M., Bowling, A. C., Newman, H. C., Jenkins, A. L. \& Goff, D. V. (1981). Glycaemic index of foods: a physiological basis for carbohydrate exchange. American Journal of Clinical Nutrition 34, 362-366.

Katz, J. R. (1934). X-ray investigation of gelatinization and retrogradation of starch in its importance for bread research. Bakers' Weekly 81, 34-37.

Katz, J. R. (1937). The amorphous part of starch in fresh bread, and in fresh pastes and solutions of starch. Recueil des Travaux Chimiques des Pays Bas et de la Belgique 18, 55-59.

Katz, J. R. \& Van Itallie, T. B. (1930). Abhandlungen zur physikalischen Chemie der Brotbereitung. V. Alle Starkearten haben das gleiche Retrogradationsspektrum (Study of the physical chemistry of breadmaking. V. All types of starch have the same retrogradation spectrum). Zeitschrift für Physikalische Chemie A150, 90-99.

Read, N. W., Welch, I. M., Austen, C. J., Barnish, C., Bartlett, C. E., Baxter, A. J., Brown, G., Compton, M. E., Hume, K. E., Storie, I. \& Worldling, J. (1986). Swallowing food without chewing: a simple way to reduce postprandial glycemia. British Journal of Nutrition 55, 43-47.

Silvester, K. R., Englyst, H. N. \& Cummings, J. H. (1995). Ileal recovery of starch from whole diets containing resistant starch measured in vitro and fermentation of ileal effluent. American Journal of Clinical Nutrition 62 , 403-411.

Sterling, C. (1978). Textural qualities and molecular structure of starch products. Journal of Texture Studies 9 , 225-255.

Walker, A. R. P. \& Walker, B. F. (1984). Glycaemic index of South African foods determined in rural blacks a population of low risk of diabetes. Human Nutrition: Clinical Nutrition 38 C, 215-222.

Wolever, T. M. S. (1990). Relationship between dietary fiber content and composition in foods and the glycaemic index. American Journal of Clinical Nutrition 51, 72-75.

Wolever, T. M. S. \& Jenkins, D. J. A. (1992). Effect of fiber and foods on carbohydrate metabolism. In Handbook of Dietary Fiber in Human Nutrition, 2nd ed., pp. 111-152 [G. Spiller, editor]. Boca Raton: CRC Press Inc.

Wolever, T. M. S., Jenkins, D. J. A., Kalmusky, J., Giordano, C., Giudici, S., Jenkins, A. L., Thompson, L. U., Wong, G. S. \& Josse, R. G. (1986). Glycaemic response to pasta: effect of surface area, degree of cooking and protein enrichment. Diabetes Care 9, 401-404.

Würsch, P., Del Vedovo, S. \& Koellreutter, B. (1986). Cell structure and starch nature as key determinants of the digestion rate of starch in legume. American Journal of Clinical Nutrition 43, 25-29. 